\title{
Study on Hemoglobin Concentration in Female Diabetic Patients
}

\author{
Hussain $M^{1}$, Nessa $A^{2}$, Haque $\mathrm{AN}^{3}$, Nasreen $S^{4}$, Begum $A^{5}$
}

Parveen $\mathrm{S}^{6}$, Ansari NB ${ }^{7}$, Muktadira ${ }^{8}$, Naznin $\mathrm{R}^{9}$

\begin{abstract}
Millions of people around the world are suffering from a destructive disease known as diabetes mellitus. In the present study hemoglobin concentration was estimated in female type 2 diabetes to observe the frequency of lowering hemoglobin level in these patients and to assess the incidence of anemia. This Descriptive type of cross sectional study was carried out in the Department of Physiology, Mymensingh Medical College, Mymensingh between the periods from July 2016 to June 2017. A total of 210 subjects were selected and were grouped as control group, Group I (70 healthy female of reproductive age, 21-45 years) and study group, Group II which was again subdivided to Group IIA (70 diabetic female of reproductive age , 21-45 years) and Group IIB (70 diabetic female of post-menopausal age, 45-70 years). Laboratory analysis of fasting serum glucose hemoglobin concentration was evaluated by the Cyanmethemoglobin (CMG) method. A comparison in hemoglobin concentration was done in between Group I and Group IIA and also in between Group IIA and Group IIB. The results were calculated and analyzed by using SPSS. For statistical analysis students unpaired 't' test was performed. The result showed that hemoglobin level was significantly decreased in the study group in comparison to the control group. It was concluded that type 2 diabetes is associated with decreased hemoglobin concentration leading to anemia.
\end{abstract}

CBMJ 2020 January: vol. 09 no. 01 P: 25-29

Key words: Type 2 Diabetes, hemoglobin concentration, anemia.

\section{Introduction}

Diabetes mellitus is a metabolic disorder of great impact worldwide. ${ }^{1}$ It is one of the major global health problems, affecting 382 million people \& accounting for 5.3 million deaths in 2013. ${ }^{2}$ By 2035 the number of affected people is expected to increase to 592 million globally. ${ }^{3}$ In the South Asian region, Bangladesh has the second largest number of adults with diabetes (5.1 million adults, $6.31 \%)^{4}$

Anemia may be indicated by deficiency in the oxygen-carrying capacity of blood due to a diminished erythrocyte mass or reduction in the hemoglobin $(\mathrm{Hb})$ concentration of the blood. ${ }^{5}$ This leads to the blood not being able to meet the body's physiological needsand It is caused by either an excessive destruction or diminished production of red blood cells. ${ }^{6}$ Anemia has a high prevalence and is considered a public health problem affecting developing and developed countries and It occurs at all stages of life, especially in pregnant women and children. ${ }^{7,8}$ Globally, 1.62 billion people are anemic, corresponding to $24.8 \%$ of the
1. Dr. Maria Hussain, Assistant Professor (CC), Department of Physiology, Community Based Medical College, Mymensingh, Bangladesh.

2. Professor Dr. Akhtarun Nessa, Department of Physiology, Mymensingh Medical College, Mymensingh, Bangladesh.

3. Dr. A. K. M. Nazmul Haque, Registrar (Hand and Microsurgery), Department of Orthopedics, Mymensingh Medical College Hospital, Mymensingh.

4. Dr. Shamima Nasreen, Assistant professor, Department of Physiology, TMSS Medical College, Bogura, Bangladesh.

5. Dr. Arifa Begum, Assistant Professor, Department of Physiology, Gazi Medical College, Khulna, Bangladesh.

6. Professor Dr. Shahanaz Parveen, Department of Physiology, Mymensingh, Bangladesh.

7. Professor Dr. Nahid Bintay Ansari, Professor (CC), Department of Physiology, Community Based Medical College, Mymensingh, Bangladesh.

8. Dr. Muktadira, Assistant professor (CC), Department of Radiology and Imaging, Community Based Medical College, Mymensingh, Bangladesh.

9. Dr. Rubaiyat Naznin, Assistant Professor, Department of Physiology, Community Based Medical College, Mymensingh, Bangladesh.

\section{Address of correspondence:}

E-mail: drmaria.bd@gmail.com

Mobile: 01717255360 
global population and the highest prevalence of $47.4 \%$ is in preschool-age children while the lowest prevalence of $12.7 \%$ is in men. ${ }^{5}$

Poorly controlled diabetes leads to complications such as nephropathy, retinopathy, and neuropathy as well as several disordered metabolic processes including oxidative stress which causes oxidative damage to tissues and cells.9 Anemia is one of the commonest blood disorders seen in patients with diabetes.10 Anemia occurs earlier and at a greater degree in patients presenting with diabetic nephropathy than those presenting with other causes of renal failure. ${ }^{11,12}$ This study aimed to determine the prevalence of anemia in female type 2 diabetes mellitus periods. The findings suggest that anemia is likely to occur in patients with diabetes with renal insufficiency, particularly when it is poorly controlled. It is therefore believed that presentation of the outcome will help increase the level of awareness and understanding of anemia among patients with diabetes, which will eventually lead to the development of interventions to optimize treatment outcomes in them.

\section{Methods}

This cross sectional study was carried out in the department of Physiology of Mymensingh Medical College, Mymensingh, Bangladesh from July 2016 to June 2017. Total number of 210 (Two hundred ten) subjects participated in this study. They were grouped as Group-I (control group): Consists of 70 apparently healthy women of reproductive age of 21-45 years of age. Group-II (study group): Consists of 140 diabetic women of both reproductive age group (21-45 yrs) and post-menopausal age group (45-70 yrs). Group II is again subdivided into: Group II A and Group II B. Group II A: consists of 70 diabetic females of reproductive age group. Group II B: consists of 70 diabetic females of post-menopausal age group. Age more than 70 years or less than 25 years, women undergo hysterectomy or receiving hormone replacement therapy, pregnant women, diagnosed case of hypothyroidism, Cushing's syndrome, polycystic ovary. Antipsychotic drug users, regular steroid users, those that have history of smoking and alcohol consumption, known case of any type of cardiac disease, such as heart failure, myocardial infarction, any type of systemic illness, such as tuberculosis, hepatitis, known case of malignancy, patient with thalassemia, hemophilia, known case of blood loss such as recent surgery, trauma or overt gastrointestinal hemorrhage and acute infectious illness conditions were excluded from the study. After selection the subjects were requested to attend the concerned center in the morning on a particular day. Under strict aseptic precaution about $3 \mathrm{ml}$ of venous blood was collected from antecubital vein by disposable syringe with a gentle pull and the blood was taken in a test tube labeled with name of subject, with date and time of blood collection. From drawn blood for estimation of hemoglobin, $0.02 \mathrm{ml}$ blood was sucked via micro pipette and poured in another test tube containing $5.0 \mathrm{ml}$ diluted Drabkin's reagent (Dilute 1 volume of the reagent with 9 volume of distilled water). That test tube was also labeled with the name of the subject, with date and time of collection. Laboratory analysis of hemoglobin concentration was evaluated by the Cyanmethemoglobin (CMG) method. For statistical analysis, Students unpaired 't' test was performed. The results were calculated and analyzed by using software, Statistical Package for the Social Science (SPSS).

\section{Results}

The study included the Hemoglobin concentration in gm/dl. Data was expressed as mean $\pm S E$.

Table I,II and figure 1 shows the Mean \pm SE of hemoglobin concentration of control group I and study group IIA were $10.96 \pm 0.81 \mathrm{gm} / \mathrm{dl}$ \& $9.29 \pm 0.75 \mathrm{gm} / \mathrm{dl}$ respectively. In study group IIA hemoglobin concentration was decreased. Result is statistically highly significant $(p<0.0001)$. The mean $( \pm S E)$ of hemoglobin concentration of study group IIA and study 
group IIB were $9.29 \pm 0.75 \mathrm{gm} / \mathrm{dl} \& 9.37 \pm 0.77$ $\mathrm{gm} / \mathrm{dl}$ respectively. Here the result is statistically not significant $(P>0.569)$.

Table I: Comparative study of Mean $\pm S E$ of Hemoglobin concentration in control and study groups by unpaired Student's 't' test

\begin{tabular}{|c|c|c|c|}
\hline $\begin{array}{l}\text { Biochemical } \\
\text { parameters }\end{array}$ & $\begin{array}{c}\text { Control group } \\
\text { Group I } n=70 \\
\text { Mean } \pm S E\end{array}$ & $\begin{array}{c}\text { Study group } \\
\text { Group II } \mathrm{A} n=70 \\
\text { Mean } \pm \mathrm{SE}\end{array}$ & $\begin{array}{c}\text { Study group } \\
\text { Group } I \mathrm{~B} \mathrm{n}=70 \\
\text { Mean } \pm \mathrm{SE}\end{array}$ \\
\hline $\mathrm{H} b \%(\mathrm{gm} / \mathrm{dl})$ & $10.96 \pm 0.81$ & $9.29 \pm 0.75$ & $9.37 \pm 0.77$ \\
\hline
\end{tabular}

Table II: Statistical analysis of hemoglobin concentration between control group and study groups and within the study groups by unpaired student's 't' test

\begin{tabular}{|c|c|c|c|}
\hline Groups & $\begin{array}{c}\text { Mean } \\
\text { difference }\end{array}$ & t Value & $\begin{array}{c}\text { level of } \\
\text { significant }\end{array}$ \\
\hline I VS IIA & 1.67 & 12.560 & $\mathrm{P}<0.0001$ \\
\hline IIA VS IIB & 0.08 & $-0.572 \mathrm{NS}$ & $\mathrm{P}>0.569$ \\
\hline
\end{tabular}

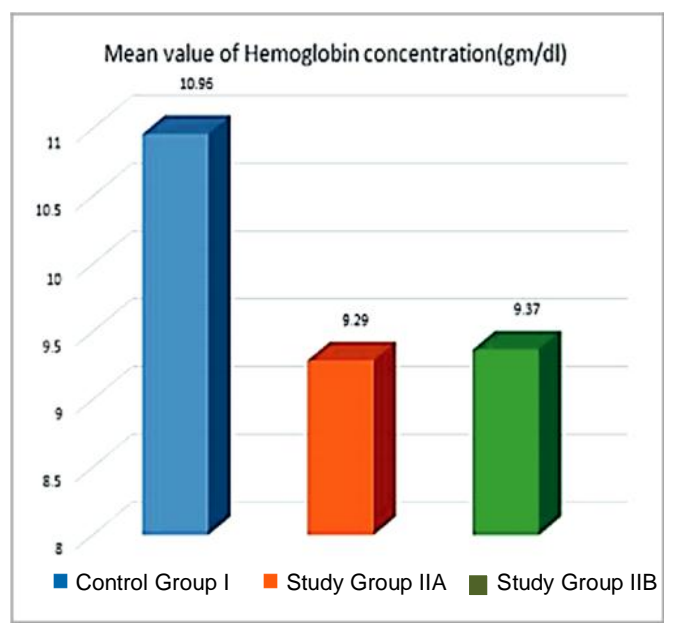

Figure 1: Bar diagram showing mean value of $\mathrm{Hb}$ concentration in different groups.

\section{Discussion}

This present work was carried out to study the effect of type 2 diabetes mellitus on hemoglobin concentration in female diabetic patients. In this study, mean ( $\pm S D$ ) hemoglobin $(\mathrm{Hb})$ concentration of control group (Group I) and study group diabetic female of reproductive age (Group IIA) and diabetic female of post-menopausal age (Group IIB) were $10.96 \pm 0.81 \mathrm{gm} / \mathrm{dl}$, $9.29 \pm 0.75 \mathrm{gm} / \mathrm{dl}$ and $9.37 \pm 0.81 \mathrm{gm} / \mathrm{dl}$ respectively. There was significantly decreased $\mathrm{Hb}$ concentration in the study group (IIA) in comparison to the control group $(p<0.0001)$. But there was no significant change of hemoglobin concentration between study group IIA and study group IIB. This result is supported by the studies done by Baisakhiya, Grag \& Singh (2016), Al-Salman (2015), Adejumo et al (2012) and Mcgill \& bell (2006).

In a study by Baisakhiya, Gang \& Singh demonstrated that anemia has been stated as a chronic complication of diabetes mellitus. Oxidative stress created by chronic hyperglycemia leads to RBC damage and is involved in the pathogenesis of anemia. ${ }^{12,13}$ In a study by Al-Salman, suggest that anemia is twice as common in diabetics compared with non-diabetics but still anemia is unrecognized in $25 \%$ of the diabetic patients. Anemia also develops earlier and is more severe in patients with diabetes than in patients with renal impairment from other causes. Anemia is a common accompaniment with diabetes and it is seen early even in the absence of renal impairment. $^{14,15}$ Anemia is common in Diabetes, potentially contributing to the pathogenesis of diabetes complication. ${ }^{16}$ Salman $\mathrm{M}$ et al. also found in his study that $55.5 \%$ diabetes patients had anemia. ${ }^{15}$ In a study of McGill \& Bell (2006), stated that anemia was more common in diabetes than without diabetes that is associated with erythropoietin deficiency. ${ }^{17}$

In a study by Shams \& Osman stated that there was a statistically significant relation between diabetes-related complications and the occurrence of anemia as micro vascular complications were frequently seen in uncontrolled and long-standing diabetes. ${ }^{18}$ According to Thomas $M$ et al. impaired renal erythropoietin release in response to declining hemoglobin levels appears to be the major contributor to anemia in diabetes. ${ }^{19}$ Thomas et al in his another study also stated that increased level of inflammatory cytokines such as interlukin-6 enhance production and secretion of hepcidin, a 
hepatic protein that inhibits intestinal iron absorption and impairs iron transport from the reticuloendothelial system to bone marrow. Erythropoietin which normally enhances iron transport from macrophages to the blood stream is impaired thereby exacerbating relative iron deficiency. ${ }^{20}$

Furthermore, anemia has a negative impact on the survival of patients with diabetes and is considered to be an important cardiovascular risk factor associated with diabetes and renal disease. ${ }^{21,22}$ Therefore there is a need for more studies on the incidence and prevalence of anemia among patients with diabetes mellitus.

\section{Conclusion}

From the present study, it may be concluded that hemoglobin concentration is significantly decreased in female diabetic patient in comparison to normal healthy female. It is also seen that type 2 diabetic persons are considered to have significant positive relation for formation of anemia and number of metabolic abnormalities that have high morbidity and mortality. So, prevention of type 2 diabetes mellitus by taking necessary steps like regular physical exercise, intake of a healthy diet and behavior therapy may help in prevention of type 2 diabetes mellitus related complication. Therefore it is important to consider each and every post-menopausal woman to undergo screening test at regular basis. As Type 2 diabetes affects hemoglobin concentration in women significantly, specific health education strategies are needed in order to prevent the emerging cardiovascular, metabolic and renal diseases.

\section{References}

1. International Diabetes Federation (IDF). IDF Diabetes Atlas 6th Edition. 2013 [cited 2014, March01]; Available: http://www.idf.org/sites /defaultffiles/EN_6E_Atlas_Full_0.pdf

2. Danaei G, Finucane MM, Lu Y, Singh GM, Cowan MJ, et al. National, regional, and global trends in fasting plasma glucose and diabetes prevalence since 1980: systematic analysis of health examination surveys and epidemiological studies with 370 countryyears and 27 million participants. Lancet 2011; 378: 31-40. pmid:21705069.

3. Mendis S, Puska P, Norrving B, World Health Organization, World Heart Federation, World Stroke Organization. Global atlas on cardiovascular disease prevention and control. Geneva: World Health Organization; 2011.

4. Guariguata L, Whiting D, Hambleton I, Beagley J, Linnenkamp U, Shaw J. Global estimates of diabetes prevalence for 2013 and projections for 2035 for the IDF Diabetes Atlas. Diabetes Res ClinPract 2013.

5. World Health Organization. Worldwide prevalence of anaemia 1993-2005.WHO Global Database on Anaemia. Geneva: WHO Press 2008; p. 7-8.

6. Ciesla B. Red blood cell production, function, and relevant red cell morphology. Haematologyin practice. Philadelphia: F. A. Davis Company 2007; p. 37-46.

7. World Health Organization. The world health report: reducing risks, promoting healthy life. Geneva: World Health Organization; 2002.

8. Comazzi S, Spagnolo V, Bonfanti $U$. Erythrocyte changes in canine diabetes mellitus: in vitro effects of hyperglycaemia and ketoacidosis. J Comp Clin Path. 2004;12(4):199-205.

9. Thomas MC, Maclsaac RJ, Tsalamandris C, Molyneaux L, Goubina I, Fulcher G, et al. The burden of anaemia in type 2 diabetes and the role of nephropathy. A cross-sectional audit.Nephrol Dial Transplant. 2004; 19:17927. 
10. El-Achkar TM, Ohmit SE, Mccullough PA, Crook ED, Brown WW, Grimm R, et al. Higher prevalence of anaemia with diabetes mellitus in moderate kidney insufficiency: The Kidney Early Evaluation Program. Kidney Int. 2005; 67(4):1483-8.

11. Bosman DR, Winkler AS, Marsden JT, Macdougall IC, Watkins PJ. Anemia with erythropoietin deficiency occurs early in diabetic nephropathy. Diabetes Care. 2001;24(3):495-9.

12. Baisakhiya $S$, Gang $P$ \& Singh $S$. Anemia in patients with diabetes mellitus with and without diabetic retinopathy. International Journal of Medical Science and Public Health. January 2016; 6(2);1.

13. Emma H. Anemia in Post-menopausal women Linked with Poor Nutrition. Journal of American Diet Association. 2011; 111:1-4.

14. Abate A, Birhan $W \&$ Alemu A. Association of anemia and renal function test among diabetes mellitus patients attending Fenote Selam Hosital, West Gojam, Northwest Ethiopia: a cross sectional study. BMC Hematol. 2013 May 7;13(1):6.D oi:10.1186/2052-1839-136.PMID:24499524;PMCID:PMC3816623.

15. Al-Salman M. Anemia in patients with diabetes mellitus: Prevalence and progression. General Med. 2015 ;3(1);162.

16. Thomas MC, Maclsaac RJ, Tsalamandris $C$, Molyneaux L, Goubina I et al. (2004). The burden of anemia in type 2 diabetes and the role of nephropathy: a cross sectional audit. Nephrol Dial Transplant 19: 1792.

17. McGill JB, Bell DS. Anemia and the role of erythropoietin in diabetes.J Diabetes Complications. 2006;0;262-72.

18. Shams N, Osmani MH. Newly diagnosed anemia in admitted diabetics, frequency, etiology and associated factors. J Coll Physicians Surg Pak. 2015;25(4):242-246. doi:04.2015/JCPSP.242246.

19. Thomas M, Tsalamandris $C$, Macisaac $R$, Jerums G. Anemia in Diabetes: an emerging complication of microvascular disease. Curr Diabetes Rev. 2001:107-26.

20. Thomas MC, Maclasaac RJ, Tsalamandris C, Jerums $G$. Elevated iron indices in patients with diabetes. Diabet Med. 2004;21:798-802.
21. Rossing $K$, Christensen PK, Hovind $P$, Tarnow L, Rossing $P$, Parving $H H$. Progression of nephropathy in type 2 diabetic patients. Kidney Int. 2004;66(4):1596-605.

22. Cusick M, Chew EY, Hoogwerf B, Agron E, Wu L, Lindley $A$, et al. Risk factors for renal replacement therapy in the Early Treatment Diabetic Retinopathy Study (ETDRS). Early Treatment Diabetic Retinopathy Study Report No. 26. Kidney Int. 2004;66(3):1173-9 